\title{
Dihydroxyacetone Phosphate
}

\section{ITS STRUCTURE AND REACTIVITY WITH $\alpha$-GLYCEROPHOSPHATE DEHYDROGENASE, ALDOLASE AND TRIOSE PHOSPHATE ISOMERASE AND SOME POSSIBLE METABOLIC IMPLICATIONS}

\author{
By S. J. REYNOLDS, D. W. YATES AND C. I. POGSON \\ Malecular Enzymology Laboratory, Department of Biochemistry, University of Bristol, Bristol BS8 $1 T D$, \\ U.K.
}

(Received 18 January 1971)

\begin{abstract}
1. Dihydroxyacetone phosphate exists in neutral aqueous solution at $20^{\circ} \mathrm{C}$ as a mixture of keto, gem-diol and enolic forms in the ratio $55: 44: 1$. 2. The three forms are freely interconvertible and rate constants for these reactions have been determined. 3. Keto-dihydroxyacetone phosphate is the primary reactive species in the reactions catalysed by $\alpha$-glycerophosphate dehydrogenase, aldolase and triose phosphate isomerase. 4. The proportion of keto form to gem-diol forms of dihydroxyacetone phosphate is temperature-dependent. At $37^{\circ} \mathrm{C}, 83 \%$ is ketodihydroxyacetone phosphate. 5. The enzymological and metabolic consequences of these results are discussed.
\end{abstract}

Many compounds containing carbonyl groups are known to exist in aqueous solution in equilibrium with their hydrates (Bell, 1966):<smiles></smiles>

Such compounds may, in addition, undergo tautomerization:<smiles>[R]CC([R])=O</smiles><smiles>[R]C=C([R])O</smiles>

The significance of this type of transformation is underlined, for example, in studies on oxaloacetic acid, solutions of which contain appreciable quantities of the enolic forms (Banks, 1961 ; Kosicki, 1962; Kosicki \& Lipovac, 1964 ; Kumler, Kun \& Shoolery, 1962; Tate, Grzybowski \& Datta, 1964). The rate of this tautomerization is enhanced by an oxaloacetic acid-specific 'tautomerase' present in most tissues (Annett \& Kosicki, 1969).

In the course of an investigation undertaken in this laboratory into the mechanism of glyceraldehyde 3-phosphate dehydrogenase [D-glyceraldehyde 3-phosphate-NAD oxidoreductase (phosphorylating), EC 1.2.1.12], it was shown that the substrate for this enzyme, D-glyceraldehyde 3phosphate, exists in aqueous solution as a mixture of the free aldehyde and gem-diol form in the ratio 1:29 (Trentham, McMurray \& Pogson, 1969).

Since dihydroxyacetone phosphate contains a carbonyl group, possibilities exist for both hydration and keto-onol tautomerization. In this paper we report experiments designed to investigate these possibilities, and discuss their relevance to linked enzyme systems.

\section{MATERIALS AND METHODS}

Chemicals. NADH, D-glyceraldehyde 3-phosphate, dihydroxyacetone phosphate and triethanolamine hydrochloride were obtained from the Boehringer Corp. (London) Ltd., London W.5, U.K. Glyceraldehyde 3-phosphate and dihydroxyacetone phosphate were prepared from their precursors by the methods of Racker, Klybas \& Schramm (1959) and Ballou \& Fisher (1956) respectively. Monohydroxyacetone (acetol, 1-hydroxypropan-2-one) was obtained from Aldrich through Ralph N. Emanuel Ltd., Alperton, Middx., U.K. Tris, as Trizma base, was obtained from Sigma (London) Chemical Co. Ltd., London S.W.6, U.K. Monohydroxyacetone phosphate (as the ketal) was a kind gift from Dr J. R. Knowles, Dyson Perrins Laboratory, University of Oxford; the free compound was prepared by the method of Ballou \& Fisher (1956). The dihydroxyacetone phosphate used in most experiments was prepared by a modification of the method of Kiessling (1934), and behaved identically in all respects with the commercial product. All other chemicals were of the highest quality obtainable from British Drug Houses Ltd., Poole, Dorset, U.K. and were used without further purification.

Enzymes. Rabbit muscle aldolase was obtained from Boehringer, and was assayed by the method described by Trentham et al. (1969). Triose phosphate isomerase (Dglyceraldehyde 3-phosphate ketol-isomerase, EC 5.3.1.1) was purified to homogeneity from chicken muscle and 
assayed as described by Trentham et al. (1969). $\alpha$-Glycerophosphate dehydrogenase (L-glycerol 3-phosphate-NAD oxidoreductase, EC 1.1.1.8) was prepared from rabbit white muscle by a modification of the method of Telegdi (1964). Activity was assayed at $25^{\circ} \mathrm{C}$ in a medium containing $0.2 \mathrm{M}$-triethanolamine, 2mM-EDTA, $0.5 \mathrm{~mm}$-dihydroxyacetone phosphate and $0.15 \mathrm{~mm}-\mathrm{NADH}$, pH 7.5 (total volume $3.0 \mathrm{ml}$ ); after addition of enzyme the reaction was followed at $340 \mathrm{~nm}$ through a $1 \mathrm{~cm}$ lightpath. The molarity of $\alpha$-glycerophosphate dehydrogenase active sites was calculated from the observed $E_{280} . E_{280}^{1 \%}=$ 5.7 as determined from dry-weight measurements (S. J. Reynolds \& D. W. Yates, unpublished work) and the molecular weight of the dimeric enzyme was taken as 70000 on the basis of thiol-group titration and NADHbinding studies (S. J. Reynolds \& D. W. Yates, unpublished work). The purity of each of the enzymes was checked with respect to contamination by the other two. The degree of contamination was too small to be of significance in any of the experiments described.

Spectroscopic and kinetic measurements. Routine steady-state assays were carried out in cuvettes of 1 or $3 \mathrm{ml}$ in either a Beckman DB or a Hilger-Gilford recording spectrophotometer. The stopped-flow apparatus was similar to that described by Gutfreund (1965). The interchangeable mixer and observation cell consisted of eight mixing jets and a $1 \mathrm{~cm}$ light-path. The solution in the observation chamber was $3 \mathrm{~ms}$ old when flow stopped. Monochromatic light was obtained from a quartztungsten-iodine lamp and a Bausch and Lomb grating monochromator. Stray light was eliminated by the use of a Wratten 18A filter. Transmission of light was measured with an EMI 9592B photomultiplier; the anode current was amplified and displayed on a Tektronix storage oscilloscope. With this instrument reactions were carried out at ambient temperature $\left(20 \pm 2^{\circ} \mathrm{C}\right)$. Stoppedflow reactions at 4 and $37^{\circ} \mathrm{C}$ were carried out with a Durrum stopped-flow spectrophotometer (kindly put at our disposal by Dr R. A. John of Cardiff University).

Proton-magnetic-resonance measurements. These spectra were recorded with a Varian HAl00 spectrometer, with tetramethylsilane as external standard $(\tau=10.00)$. Dihydroxyacetone phosphate solutions were prepared as described above and neutralized to $\mathrm{pH} 7.0$ with $\mathrm{NaOH}$. These solutions were freeze-dried and the residues were dissolved in $\mathrm{D}_{2} \mathrm{O}$ to give final concentrations between 80 and $100 \mathrm{~mm}$.

Infrared spectroscopy. I.r. spectra were recorded on a Perkin-Elmer model 225 spectrometer. Samples in $\mathrm{D}_{2} \mathrm{O}$ were placed in a $\mathrm{CaF}_{2}$ cell with $0.05 \mathrm{~mm}$ light-path length. Readings were taken against a reference cell of similar path length filled with $\mathrm{D}_{2} \mathrm{O}$. Cells were scanned between 1800 and $1600 \mathrm{~cm}^{-1}$; both cells were then stored at $4^{\circ} \mathrm{C}$ for $2 \mathrm{~h}$. At the end of this period, the cells were scanned immediately and at $70 \mathrm{~s}$ intervals until no further change in transmission was recorded. We are grateful to Dr P. L. Goggin for his assistance with these measurements.

Iodination studies. Reactions were carried out in a medium consisting of $0.1 \mathrm{M}$-sodium phosphate, $\mathrm{pH} 7.0$, containing $1 \mathrm{M}-\mathrm{KI}$ and $\mathrm{KI}_{3}$ at various concentrations. $\mathrm{KI}_{3}$ was generated by suitable addition of $5 \mathrm{mM}-\mathrm{I}_{2}$ in M-KI. The reactions, in a final volume of $3.0 \mathrm{ml}$ with a $1 \mathrm{~cm}$ light-path, were initiated by suitable addition of monohydroxyacetone, dihydroxyacetone or their respec- tive phosphates, and were followed at $351 \mathrm{~nm}$ and $30^{\circ} \mathrm{C}$ in a Hilger-Gilford recording spectrophotometer. The molar extinction coefficient of $\mathrm{KI}_{3}$ under these conditions was determined as 13050 .

\section{RESULTS AND DISCUSSION}

Stopped-flow studies with a-glycerophosphate dehydrogenase. This enzyme catalyses the reaction:

$$
\begin{aligned}
& \text { Dihydroxyacetone- } P+ \mathrm{NADH}+\mathrm{H}^{+} \rightleftharpoons \\
& \alpha \text {-glycerophosphate }+\mathrm{NAD}^{+}
\end{aligned}
$$

NADH oxidation was observed at $340 \mathrm{~nm}$ after rapid mixing of solutions from the two syringes of the stopped-flow spectrophotometer. The first syringe contained $\alpha$-glycerophosphate dehydrogenase, NADH and buffer; the second syringe contained dihydroxyacetione phosphate and buffer.

Experiments with high concentrations of enzyme (5-50 $\mu \mathrm{M}$ active sites) and low concentrations of dihydroxyacetone phosphate $(5-50 \mu \mathrm{M}$, which is equal to or less than the NADH concentration) gave results showing biphasic kinetics (Fig. 1). Whereas the fast step was dependent on enzyme concentration the rate of the slow step was independent of this parameter.

The ratio of NADH oxidized in the fast step to that oxidized in the slow step was 55:45. This value was independent of enzyme concentration (range 5-50 $\mu \mathrm{M}$ active sites), dihydroxyacetone phosphate concentration (range $5-50 \mu \mathrm{M}$ ), $\mathrm{pH}$

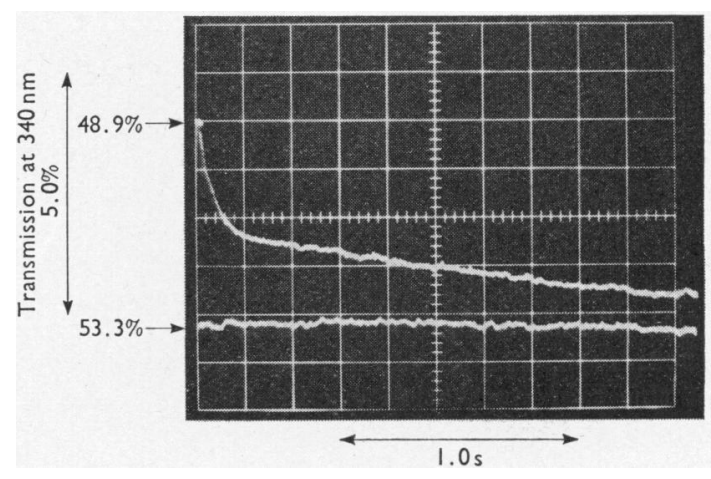

Fig. 1. Spectrophotometric record of a stopped-flow observation of the rate of NADH oxidation at $340 \mathrm{~nm}$ at $20^{\circ} \mathrm{C}$ in a reaction mixture containing dihydroxyacetone phosphate $(5 \mu \mathrm{M}), \alpha$-glycerophosphate dehydrogenase $(30 \mu \mathrm{M}$ catalytic sites), NADH $(50 \mu \mathrm{M})$ in triethanolamine hydrochloride buffer $(0.1 \mathrm{M})$ and EDTA $(2 \mathrm{mM})$ adjusted to pH 7.5 with $\mathrm{NaOH}$. One syringe contained dihydroxyacetone phosphate, the other the enzyme and NADH; the other components were present at equal concentrations in both syringes. After a few seconds, the oscilloscope was retriggered to record the end-point of the reaction. 
(over the range pH3-9) and buffer (67 mM-sodium phosphate, $0.1 \mathrm{~m}$-triethanolamine or $0.1 \mathrm{~m}$-tris).

Identical results were obtained in experiments where $\alpha$-glycerophosphate dehydrogenase and dihydroxyacetone phosphate were pre-incubated and mixed with NADH in the stopped-flow apparatus.

The form or forms that react rapidly with $\alpha$ glycerophosphate dehydrogenase (i.e. $55 \%$ of the total dihydroxyacetone phosphate) may be designated the 'active' species. The slow reaction may, therefore, be assigned to the interconversion of 'inactive' (45\%) into 'active' species:
Proton magnetic resonance. Proton-magneticresonance spectroscopy may be used to distinguish between free and hydrated carbonyls in solution (Lombardi \& Sogo, 1960; Hine \& Houston, 1965; Hooper, 1967; Gray \& Barker, 1970).

Dihydroxyacetone phosphate $(83 \mathrm{~mm})$ in $\mathrm{D}_{2} \mathrm{O}$ gave several peaks. These were similar to those obtained by Gray \& Barker (1970), but showed a general downfield shift from the values reported in their paper (possibly due to $\mathrm{pH}$ or temperature differences).

The doublet at $5.12 \tau(J 8 \mathrm{~Hz})$ may be assigned

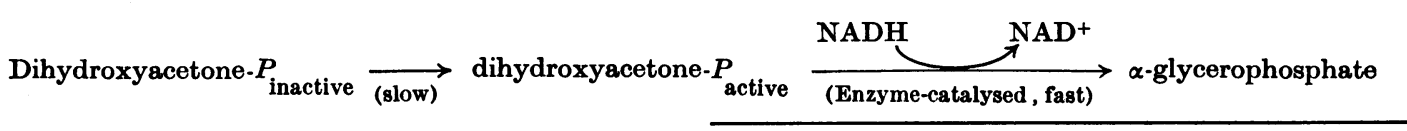

There are a number of possible structures for dihydroxyacetone phosphate, namely free keto (I), hydrated keto or gem-diol (II), cyclic dimer (Gardiner, 1966) (III) and enolic forms (IV).

For conditions similar to those used in our experiments we may eliminate two of these possibilities. (a) If the slow 'interconversion' reaction involved dissociation of a dimeric species, then the ratio of 'active' to 'inactive' forms should show a dependence on the concentration of dihydroxyacetone phosphate; such a dependence has not been observed, the ratio 55:45 being maintained over a tenfold change in dihydroxyacetone phosphate concentration. (b) The hydrogen-bonded enol form (IVc) exists only in relatively strong alkaline solutions (Sellinger \& Miller, 1958).

To determine the proportions of the remaining forms existing in aqueous dihydroxyacetone phosphate solutions, a number of physical techniques were employed. to the $-\mathrm{CH}_{2} \mathrm{OPO}_{3}{ }^{2-}$ group of the free keto form of dihydroxyacetone phosphate (Gray \& Barker, 1970), the splitting being due to the proximity of the phosphate group (Crutchfield, Callis, Irani \& Roth, 1962). A singlet superimposed on one of the doublet peaks at $5.08 \tau$ is assigned to the $-\mathrm{CH}_{2} \mathrm{OH}$ group of the free keto form of dihydroxyacetone phosphate.

A further upfield doublet at $5.81 \tau(J 8 \mathrm{~Hz})$ is ascribed to the $-\mathrm{CH}_{2} \mathrm{OPO}_{3}{ }^{2-}$ group of the gem-diol form of dihydroxyacetone phosphate, with splitting again due to the phosphate. The corresponding singlet $\left(-\mathrm{CH}_{2} \mathrm{OH}\right.$ group) is at $6.06 \tau$.

Integrals were measured across the complete spectrum and showed that under the conditions prevailing (neutral pH, fully ionized form) $61 \%$ could be accounted for as the keto form of dihydroxyacetone phosphate and $39 \%$ as the hydrated gem-diol form of dihydroxyacetone phosphate. These values agree well with those of Gray \& Barker

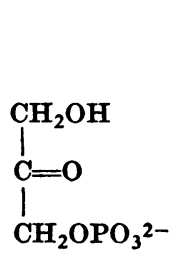

(I)<smiles>O=[Po+]([O-])[OH2+]</smiles>

(a)

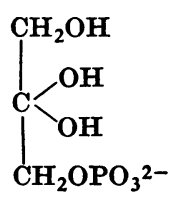

(II)<smiles>O=C(O)CCOC(=O)O</smiles>

(b)

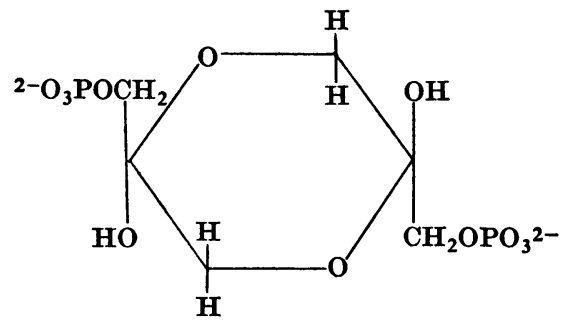

(III)<smiles>O=[R6]1COCC(O)C1</smiles>

(c) 
(1970), who report 63 and $55 \%$ of the keto form at 37 and $25^{\circ} \mathrm{C}$ respectively.

The assignments of the various 'peaks' were checked by re-running the spectrum after addition of sufficient triose phosphate isomerase to effect equilibration with glyceraldehyde 3-phosphate. At equilibrium the contribution by the glyceraldehyde 3-phosphate present (4.3\%) to the overall spectrum is insignificant. Triose phosphate isomerase is known to effect a stereospecific exchange of one of the $-\mathrm{CH}_{2} \mathrm{OH}$ protons with the solvent (Reider \& Rose, 1959) and thus induce a 50\% decrease in the integrals across $-\mathrm{CH}_{2} \mathrm{OH}$ absorption peaks. In confirmation of this, the calculated decreases were observed at both 5.08 and $6.06 \tau$.

Infrared spectroscopy. I.r. spectra of $83 \mathrm{~mm}$ dihydroxyacetone phosphate in $\mathrm{D}_{2} \mathrm{O}$ show a peak, attributable to the carbonyl function, at $1735 \mathrm{~cm}^{-1}$. Since the hydration of carbonyl groups is a temperature-dependent reaction (Bell, 1966), the

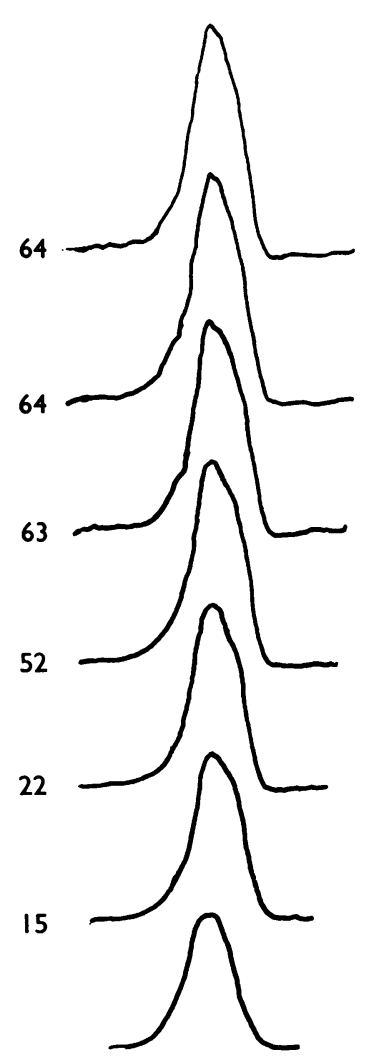

Fig. 2. I.r.-absorption spectra at $1735 \mathrm{~cm}^{-1}$. Dihydroxyacetone phosphate was present in $\mathrm{D}_{2} \mathrm{O}$ at $83 \mathrm{~mm}$; spectra were recorded at $70 \mathrm{~s}$ intervals after the removal of the sample from $4^{\circ} \mathrm{C}$ to room temperature. The earliest record is at the bottom of the figure and numbers refer to the percentage increase in peak area with time. effect of temperature on the proportion of the free keto form of dihydroxyacetone phosphate may be investigated qualitatively by following absorption changes at $1735 \mathrm{~cm}^{-1}$.

Local heating due to the i.r. radiation allows monitoring of the effect of increasing temperature by continuous repeated scanning between 1800 and $1600 \mathrm{~cm}^{-1}$. The results (Fig. 2) show that absorption, and hence the percentage of the keto form, increases with increasing temperature. This is in accord with the results from proton-magneticresonance measurements.

Identical results were obtained when the cell was recooled and the experiment repeated, thus demonstrating that the temperature-dependent hydration is freely reversible.

Iodination studies. Enols are characterized by their reactivity towards iodine (Hine, 1956; Bruice \& Benkovic, 1966). Both the concentration and rate of formation of enolic species in solution may thus be determined by following iodine uptake from potassium tri-iodide at $351 \mathrm{~nm}$. Spectroscopic studies (as described in the Materials and Methods section) were carried out both with dihydroxyacetone phosphate and with the reference compounds monohydroxyacetone (1-hydroxypropan-2-one, acetol), monohydroxyacetone phosphate (1-hydroxypropan-2-one 1-phosphate, acetol phosphate), and dihydroxyacetone (1,3dihydroxy propan-2-one).

The progress curves of reactions were similar in all cases. An initial rapid $\left[\mathrm{I}_{3}{ }^{-}\right]$-dependent reaction was attributed to reaction of the free enol present. The subsequent slower $\left[\mathrm{I}_{3}{ }^{-}\right]$-independent reaction was attributed to formation of enolic species by tautomerization. The total proportions of enolic species and the rates of their formation are given in Table 1.

It is apparent that the proportion of the enol form of dihydroxyacetone phosphate in the solutions used in the stopped-flow experiments is insufficient for this species to account for the slower phase (45\% of the reaction.

Temperature dependence of the 'active'/'inactive' dihydroxyacetone phosphate ratio. At ambient temperatures (approx. $20^{\circ} \mathrm{C}$ ) dihydroxyacetone phosphate exists as the free keto form and hydrated keto form in approximately equal concentrations. It is thus difficult to ascertain with any certainty which of these two forms is active as a substrate for $\alpha$-glycerophosphate dehydrogenase. Thei.r. spectra reported above show that the amount of the free keto form of dihydroxyacetone phosphate is increased at higher and decreased at lower temperatures. Rapid reactions studied over a range of temperature should therefore help to pinpoint the identity of the active form of dihydroxyacetone phosphate. 


\section{Table 1. Proportion of enolic forms of various ketones and their phosphate esters in aqueous solution}

Reactions with $\mathrm{KI}_{3}$ were followed spectrophotometrically at $351 \mathrm{~nm}$ and $30^{\circ} \mathrm{C}$. Other conditions were as described in the Materials and Methods section.

$\begin{array}{llc} & \% \text { enol } & \text { Rate of enolization } \\ \text { Monohydroxyacetone } & 0.04 & 1.1 \times 10^{-7} \mathrm{~s}^{-1} \\ \text { Monohydroxyacetone phosphate } & 0.17 & 9.1 \times 10^{-6} \mathrm{~s}^{-1} \\ \text { Dihydroxyacetone } & 0.02 & 3.9 \times 10^{-9} \mathrm{~s}^{-1} \\ \text { Dihydroxyacetone phosphate } & 1.0 & 7.9 \times 10^{-5} \mathrm{~s}^{-1}\end{array}$

Acetone $\quad 0.00025$

(Schwarzenbach \& Wittwer, 1947

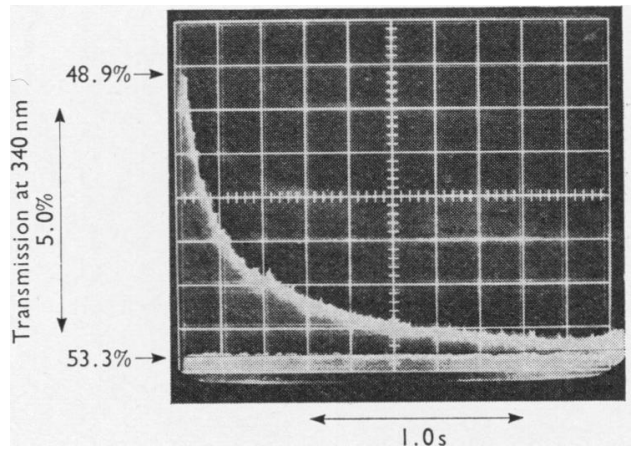

Fig. 3. Spectrophotometric record at $340 \mathrm{~nm}$ of a stoppedflow observation of the rate of $\mathrm{NADH}$ oxidation at $37^{\circ} \mathrm{C}$. The reaction mixture contained dihydroxyacetone phosphate $(12.5 \mu \mathrm{M}), \mathrm{NADH}(50 \mu \mathrm{M}), \alpha$-glycerophosphate dehydrogenase ( $35 \mu \mathrm{M}$ catalytic sites) in triethanolamine hydrochloride buffer (0.1 M) and EDTA (2 mM) adjusted to $\mathrm{pH} 7.5$ with $\mathrm{NaOH}$. One syringe contained dihydroxyacetone phosphate, the other enzyme and NADH; the other components were present at equal concentrations in both syringes. After a few seconds the oscilloscope was retriggered to record the end-point of the reaction.

Stopped-flow experiments at various temperatures were carried out in a thermostatically controlled Durrum stopped-flow spectrophotometer. Results at $20^{\circ} \mathrm{C}$ confirmed those obtained with a different instrument. At $4^{\circ} \mathrm{C}$ the 'active'/'inactive' dihydroxyacetone phosphate ratio (i.e. the ratio of the amplitude of the fast to the slow step) was 15:85. form (structure I), although the participation of enolic species cannot be excluded.

An aqueous solution at $20^{\circ} \mathrm{C}$ and neutral $\mathrm{pH}$, therefore, consists of free keto, hydrated keto ( $\mathrm{gem}$ diol) and enol forms in the proportions $55: 44: 1$.

Since the slow rate observed in the stopped-flow studies is attributable to the 'dehydration' reaction, one may calculate the two first-order rate constants for the interconversion:<smiles></smiles>

At $20^{\circ} \mathrm{C} k_{+1}=0.44 \mathrm{~s}^{-1}$ and $k_{-1}=0.36 \mathrm{~s}^{-1}$.

Reaction with periodate. Periodate cleaves between adjacent carbon atoms where both bear hydroxyl groups (Malaprade, 1928):

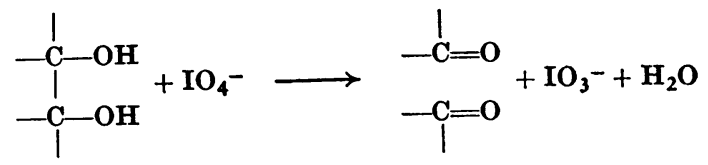

Included in the group of compounds reactive with periodate are those hydroxyaldehydes and hydroxyketones that may assume a vicinal-diol configuration by hydration of the carbonyl function (Fleury \& Lange, 1932; Malaprade, 1934).

The gem-diol form of dihydroxyacetone phosphate should therefore react with periodate directly :<smiles>C[C-][O+][O-]</smiles>

At $37^{\circ} \mathrm{C}$ this ratio became 83:17 (Fig. 3). These observations strongly suggest that the active species of dihydroxyacetone phosphate in its reaction with $\alpha$-glycerophosphate dehydrogenase is the free keto
This is analogous to the reaction of periodate with dihydroxyacetone (Fleury \& Lange, 1932; Fleury \& Fiévet-Gurnaid, 1947). If this reaction is faster than the hydration of keto-dihydroxyacetone phosphate, Bioch. 1971, 122 


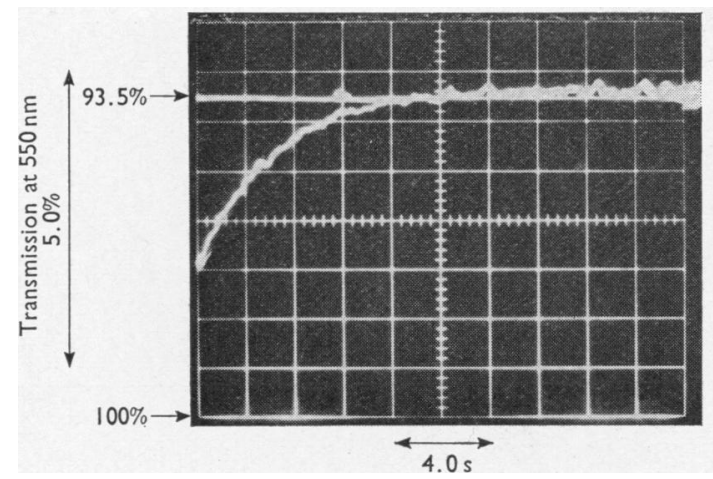

Fig. 4. Spectrophotometric record of a stopped-flow observation at $550 \mathrm{~nm}$ and $20^{\circ} \mathrm{C}$ of the rate of proton release in a reaction mixture containing $\mathrm{HIO}_{4}(0.5 \mathrm{M})$, dihydroxyacetone phosphate $(50 \mu \mathrm{M})$ and Methyl Orange $(0.0016 \%)$ at $\mathrm{pH} 4.2$. The first syringe contained dihydroxyacetone phosphate, the second $\mathrm{HIO}_{4}$. Methyl Orange was present in both. The $\mathrm{pH}$ of both syringes was previously adjusted to $\mathrm{pH} 4.2$ by careful addition of $0.1 \mathrm{~m}$ $\mathrm{NaOH}$. After a few seconds the oscilloscope was retriggered to record the end-point of the reaction.

then by measuring proton production it should be possible to observe a biphasic progress curve with the relative size of the fast reaction representing the original gem-diol form of dihydroxyacetone phosphate, and the slow reaction showing the rate of hydration of the keto form.

Fig. 4 shows the result of such stopped-flow experiments involving Methyl Orange as indicator at $\mathrm{pH}$ 4.2. At $20^{\circ} \mathrm{C} 46 \%$ of the total dihydroxyacetone phosphate reacts in the fast step and the remaining $54 \%$ reacts more slowly with a reactionrate constant of $0.35 \mathrm{~s}^{-1}$. This is very close to the value obtained from other experiments for the formation of 'enzymically inactive' dihydroxyacetone phosphate from 'active' dihydroxyacetone phosphate.

Linked systems. In physiological systems, the situation regarding dihydroxyacetone phosphate is more complex. To assess the importance of the non-enzymic dihydroxyacetone phosphate interconversions hitherto described, it is necessary to extend these studies to include aldolase and triose phosphate isomerase, which can both bind dihydr. oxyacetone phosphate.

In a coupled reaction system with both triose phosphate isomerase and $\alpha$-glycerophosphate dehydrogenase, glyceraldehyde 3-phosphate will be isomerized to dihydroxyacetone phosphate which will then be reduced by NADH. The rate at which NADH is oxidized will depend upon whether triose phosphate isomerase liberates dihydroxyacetone phosphate as the free keto form or as the hydrated keto form. This is illustrated in Scheme 1.

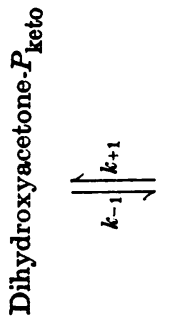


If triose phosphate isomerase is present in a very high concentration then a known amount of dihydroxyacetone phosphate may be produced from glyceraldehyde 3-phosphate extremely rapidly and this concentration of dihydroxyacetone phosphate maintained. It is known, however, that glycer-

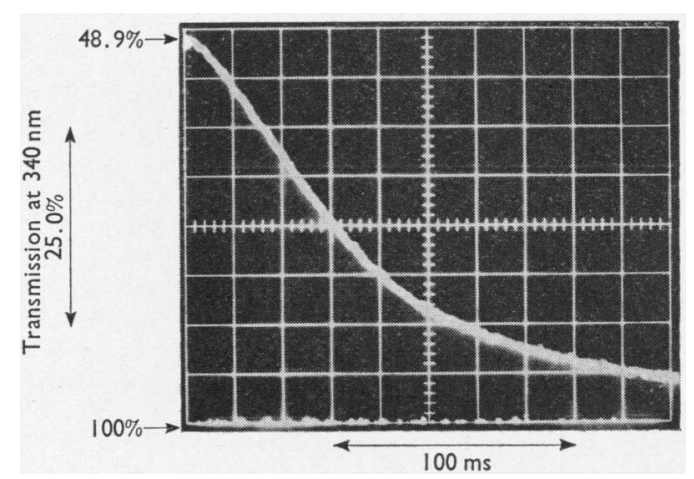

Fig. 5. Spectrophotometric record of the rate of NADH oxidation in a coupled reaction catalysed by $\alpha$-glycerophosphate dehydrogenase and triose phosphate isomerase. Stopped-flow traces were recorded at $340 \mathrm{~nm}$ and $20^{\circ} \mathrm{C}$. The reaction mixtures contained glyceraldehyde 3phosphate (1.5 mM), triose phosphate isomerase $(0.2 \mathrm{mg} /$ ml final concentration), $\alpha$-glycerophosphate dehydrogenase $(30 \mu \mathrm{M}$ catalytic sites), $\mathrm{NADH}(50 \mu \mathrm{M})$ in triethanolamine hydrochloride buffer $(0.1 \mathrm{M})$ and EDTA ( $2 \mathrm{~mm}$ ) adjusted to $\mathrm{pH} 7.5$ with $\mathrm{NaOH}$. The first syringe contained NADH and the enzymes, the second contained glyceraldehyde 3-phosphate. The other components were present at equal concentrations in both syringes. After a few seconds the oscilloscope was retriggered to record the end-point of the reaction. aldehyde 3-phosphate in aqueous solution exists in an aldehyde and a diol form (Trentham et al. 1969); only glyceraldehyde 3-phosphate is active as a substrate for triose phosphate isomerase. The diol/ aldehyde form ratio is 29 and the transformation from the one to the other is relatively slow. It is important, therefore, to ensure that this reaction at no time becomes rate limiting in the linked system. This is most easily achieved by using glyceraldehyde 3-phosphate at 29 times the apparent necessary concentration, in which case only the aldehyde form is involved.

The rate of $\mathrm{NADH}$ oxidation (or $\mathrm{NAD}^{+}$production) can be described by:

$$
\begin{array}{r}
\frac{\mathrm{d}\left[\mathrm{NAD}^{+}\right]}{\mathrm{d} t}=k_{0}[\text { glycerol-1- } P \text { dehydrogenase }] / 1+ \\
K_{m} \text { (dihydroxyacetone- } P \text { ) }
\end{array}
$$

if Scheme 1 is followed, where $k_{0}$ is the catalyticcentre activity of $\alpha$-glycerophosphate dehydrogenase appropriate to the concentration of dihydroxyacetone phosphate $e_{\text {keto }}$ that is maintained in equilibrium with glyceraldehyde 3 -phosphate ald $_{\text {. If }}$ dihydroxyacetone phosphat $\theta_{\text {diol }}$ is liberated from triose phosphate isomerase then the diol-keto transformation will be rate limiting at high concentrations of $\alpha$-glycerophosphate dehydrogenase. Under these conditions:

$$
\left(\frac{\mathrm{d}\left[\mathrm{NAD}^{+}\right]}{\mathrm{d} t}\right)_{\max .}=k_{+1}\left[\text { dihydroxyacetone }-P_{\mathrm{diol}}\right]
$$

where [dihydroxyacetone- $P_{\text {diol }}$ ] is the concentration of the diol form that is maintained in equilibrium with glyceraldehyde 3-phosphat $e_{\text {ald }}$.
Glyceraldehyde-3-P $P_{\text {ald }}$ $\rightleftharpoons \quad$ Dihydroxy
$\|$ Dihydroxyacetone- $P_{\text {diol }}$ (ii)

\begin{abstract}
Glyceraldehyde-3- $P_{\text {ald }}$
\end{abstract}
Dihydroxyacetone- $P_{\text {keto }} \underbrace{\stackrel{\substack{\alpha-G l y c e r o l-P \\ \text { dehydrogenase }}}{\mathrm{NAD}^{+}}}_{\substack{\text { NADH } \\+\mathrm{H}^{+}}}$D-Glycerol-1-P

Dihydroxyacetone- $\boldsymbol{P}_{\text {diol }}$

Aldolase-dihydroxyacetone- $\boldsymbol{P}_{\text {diol }}$

Scheme 2. 
When $\alpha$-glycerophosphate dehydrogenase, triose phosphate isomerase and NADH were mixed rapidly with glyceraldehyde 3-phosphate (to give $50 \mu$ M-dihydroxyacetone phosphate in a stopped-flow experiment (Fig. 5), the rate of NADH oxidation was $125 \times 10^{-6} \mathrm{M}^{\cdot} \mathrm{s}^{-1}$. When the same enzyme solution was mixed rapidly with $50 \mu \mathrm{M}$-dihydroxyacetone phosphate instead of the glyceraldehyde 3-phosphate then the usual biphasic reaction was seen. The fast rate of NADH oxidation was $130 \times$ $10^{-6} \mathrm{M} \cdot \mathrm{s}^{-1}$. From these experiments we conclude that triose phosphate isomerase must liberate the keto form of dihydroxyacetone phosphate.

Difficulties were encountered in attempts to carry out similar experiments with the linked system D-fructose 1,6-diphosphate, aldolase and $\alpha$-glycerophosphate dehydrogenase. These are attributed to the relatively low catalytic-centre activity of aldolase and the possibility of a tight binding constant between dihydroxyacetone phosphate and this enzyme.

These difficulties were obviated in a second experimental approach in which we investigated the ability of aldolase to act as a competitor with $\alpha$ glycerophosphate dehydrogenase for the keto form of dihydroxyacetone phosphate. The two possible pathways are shown in Scheme 2. If pathway (i) is operative with aldolase binding the keto form of dihydroxyacetone phosphate and competing successfully with $\alpha$-glycerophosphate dehydrogenase, the fast rate previously observed in the absence of aldolase will be decreased. If, however, pathway (ii) is operative with aldolase binding only dihydroxyacetone phosphate ${ }_{\text {diol }}$, then the fast rate of NADH oxidation will be independent of and unaffected by the aldolase concentration. [Similar apparent independence of the aldolase concentration could, of course, arise from pathway (i) if the dissociation constant for dihydroxyacetone phosphate to aldolase was very large.]

Aldolase was found to compete effectively with $\alpha$-glycerophosphate dehydrogenase (Figs. 5 and 6). At $0.1 \mathrm{~mm}$-aldolase (active sites), the rate of NADH oxidation was decreased from $425 \times 10^{-6}$ to $34 \times$ $10^{-6} \mathrm{M} \cdot \mathrm{s}^{-1}$. This inhibition was dependent on the concentration of aldolase added.

We may conclude therefore that the three enzymes, $\alpha$-glycerophosphate dehydrogenase, aldolase and triose phosphate isomerase, all use ketodihydroxyacetone phosphate and that the interconversions of this with the gem-diol form is not a component of any metabolic pathway. At the same time it is difficult to eliminate the possibility that enolic species participate in these reactions, although the low concentrations and slow rates of formation of these forms ensure that their contribution is quantitatively of little significance.

Equilibrium constant of the triose phosphate iso-

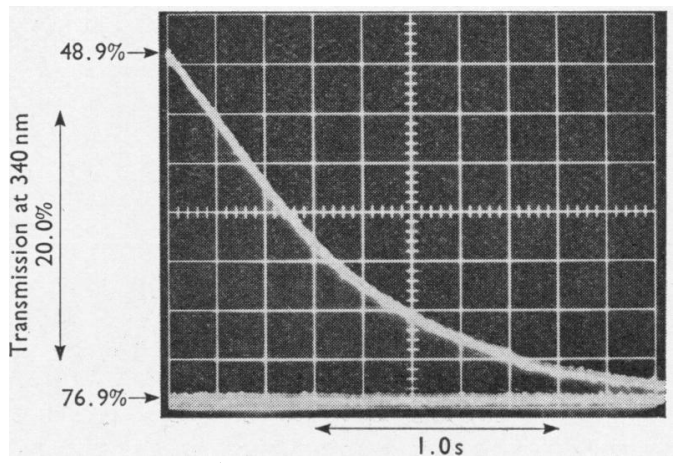

Fig. 6. Spectrophotometric record of the rate of NADH oxidation in a coupled reaction catalysed by $\alpha$-glycerophosphate dehydrogenase and triose phosphate isomerase in the presence of aldolase. Stopped-flow traces were recorded at $340 \mathrm{~nm}$ and $20^{\circ} \mathrm{C}$. The reaction mixtures contained glyceraldehyde 3-phosphate $(1.5 \mathrm{~mm})$, triose phosphate isomerase $(0.2 \mathrm{mg} / \mathrm{ml}$ final concentration), $\alpha$-glycerophosphate dehydrogenase ( $30 \mu \mathrm{M}$ catalytic sites), NADH $(50 \mu \mathrm{M})$, aldolase $(100 \mu \mathrm{M}$ catalytic sites) in triethanolamine hydrochloride buffer $(0.1 \mathrm{~m})$ and EDTA ( $2 \mathrm{~mm}$ ) adjusted to $\mathrm{pH} 7.5$ with $\mathrm{NaOH}$. The first syringe contained the enzymes and $\mathrm{NADH}$, the second contained glyceraldehyde 3-phosphate. The other components were present at equal concentrations in both syringes. After a few seconds the oscilloscope was retriggered to record the end-point of the reaction.

merase reaction. Triose phosphate isomerase catalyses the reaction:

\section{Glyceraldehyde-3- $P \rightleftharpoons$ Dihydroxyacetone- $P$}

Various estimates have been made of the equilibrium constant $\left(K_{\mathrm{eq} .}=\right.$ dihydroxyacetone phosphate/glyceraldehyde 3-phosphate) for this reaction, namely 24 at $25^{\circ} \mathrm{C}$ (Meyerhof \& JunowiczKocholaty, 1943); 28 at $38^{\circ} \mathrm{C}$ (Lowry \& Passonneau, 1964); 22 at $25^{\circ} \mathrm{C}$ (Burton \& Waley, 1968); and $22 \pm 0.246$ at $38^{\circ} \mathrm{C}$ (Veech, Raijman, Dalziel \& Krebs, 1969). This last value of 22 was derived from 30 observations and will be taken as the established value for the purposes of this discussion.

The observations of triose phosphate structures in this and a previous paper (Trentham et al. 1969) lead to two primary conclusions. (1) The hitherto accepted $K_{\text {eq. }}$ for the triose phosphate isomerase reaction clearly refers to the overall reaction (Scheme 3). If one restricts consideration to the enzymic step alone, however, $K_{\text {eq. }}$ is markedly increased due to the disparity in the relative hydration of the two substrates (Table 2). The percentages of the active substrate species are temperature-dependent (Kirschner, 1971, and this paper) but the combined effects of the changes brought about by a temperature rise from $25^{\circ} \mathrm{C}$ to 
<smiles>O=POCC(O)(O)CO</smiles><smiles>C=CC(=O)CO</smiles>

Diol $44 \%$
Keto $\mathbf{5 5 \%}$<smiles>C=[Tl]</smiles><smiles>O=[R6]OCC(O)=CO</smiles><smiles>C=C</smiles><smiles>O=CC(O)COP(=O)(O)O</smiles>

Aldehyde 3.3\%<smiles></smiles>

Diol 96.7\%

Enol

$1 \%$

Dihydroxyacetone phosphate

Glyceraldehyde 3-phosphate

Scheme 3. Overall reaction.

Table 2. Recalculated kinetic constants for triose phosphate isomerase from various sources

(a) Equilibrium data

Glyceraldehyde-3- $P_{\text {ald }}(\%)$

Dihydroxyacetone- $P_{\text {keto }}(\%)$

$K_{\text {eq. }}$ (dihydroxyacetone- $P /$ glyceraldehyde-3- $P$ )

Original value

Recalculated

$\Delta G^{0}(\mathrm{kcal} / \mathrm{mol})$

Original value

Recalculated

(b) Kinetic parameters

$K_{m}$ (glyceraldehyde-3- $P$ )

Rabbit muscle (Burton \& Waley, 1968)

Rabbit muscle (Krietsch et al. 1970)

Rabbit liver (Krietsch et al. 1970)

Human erythrocyte (Schneider, Valentine,

Hattori \& Heins, 1965)

Yeast (Krietsch et al. 1970)

$K_{m}$ (dihydroxyacetone- $P$ )

Rabbit muscle (Burton \& Waley, 1968)

Rabbit muscle (Krietsch et al. 1970)

Rabbit liver (Krietsch et al. 1970)

Yeast (Krietsch et al. 1970) $20^{\circ} \mathrm{C}$

3.3 (Trentham et al. 1969) 55

22
367

$-1.82$

$-3.49$ $37^{\circ} \mathrm{C}$

$4.3\left(40^{\circ} \mathrm{C}\right.$; Kirschner, 1970) 32

22 (Veech et al. 1969) 420

$-1.90$

$-\mathbf{3 . 1 7}$

$\begin{array}{cc}\text { Reported (M) } & \text { Recalculated (M) } \\ 4.6 \times 10^{-4} & 15 \times 10^{-6} \\ 3.2 \times 10^{-4} & 11 \times 10^{-6} \\ 3.2 \times 10^{-4} & 11 \times 10^{-6} \\ 3.5 \times 10^{-4} & 12 \times 10^{-6} \\ & \\ 12.7 \times 10^{-4} & 42 \times 10^{-6} \\ & \\ 8.7 \times 10^{-4} & 4.8 \times 10^{-4} \\ 6.2 \times 10^{-4} & 3.4 \times 10^{-4} \\ 6.0 \times 10^{-4} & 3.3 \times 10^{-4} \\ 12.3 \times 10^{-4} & 6.8 \times 10^{-4}\end{array}$

$37^{\circ} \mathrm{C}$ produce little, if any, significant change in the position of the triose phosphate isomerase equilibrium. (2) The $K_{m}$ values obtained for the two substrates during kinetic analyses in vitro are similarly related to the total concentrations of all species of the substrate molecules. Values for triose phosphate isomerase from various sources, recalculated to allow for active substrate species only, are given in
Table 2. The $K_{m}$ value for glyceraldehyde 3 phosphate $e_{\text {ald }}$ is seen to be very similar to the $K_{t} 6.7 \times$ $10^{-6} \mathrm{M}$ reported for the triose phosphate isomerase inhibition by 2-phosphoglycollate (Wolfenden, 1969). This fact might be taken to indicate that 2 phosphoglycollate is merely a conventional substrate analogue, although pronounced differences between the $\mathrm{pH}$-dependencies of substrate and 
inhibitor binding have been observed (Wolfenden, 1970).

In view of the fact that triose phosphates are normally present in mammalian tissues at concentrations close to those of the enzymes involved in their metabolism (Table 3), it is of interest to consider their chemical states in vivo.

The total concentration of glyceraldehyde 3phosphate dehydrogenase, triose phosphate isomerase and aldolase active sites in rat liver cytosol is nearly tenfold greater than the steady-state concentration of glyceraldehyde 3-phosphate reported by Veech et al. (1969). If one assumes that the binding constants for glyceraldehyde 3-phosphate for the various enzymes are similar to or smaller than the $K_{m}$ values, it is highly probable that a very large proportion of the measurable glyceraldehyde 3-phosphate is bound in vivo, and thus 'fixed' as aldehyde (Trentham et al. 1969). The pool of free glyceraldehyde 3-phosphate and hence of the gem-diol form would be correspondingly very small. Even if it is allowed that aldolase (Veech et al. 1969) and triose phosphate isomerase are substantially saturated with fructose diphosphate and dihydroxyacetone phosphate respectively, the concentration of glyceraldehyde 3-phosphate dehydrogenase alone may be high enough to maintain a very small steady-state pool of unbound glyceraldehyde 3-phosphate. In the event, however, of a sizeable proportion of the total glyceraldehyde 3-phosphate dehydrogenase being present as the 3-phosphoglyceroyl-enzyme (as may be the case during glycolysis; D. R. Trentham, personal communication), the pool of free glyceraldehyde 3-phosphate might then constitute the largest part of the total glyceraldehyde 3-phosphate with resulting concentrations of glyceraldehyde 3-phosphate $e_{\text {ald }}$ of about $0.1 \mu \mathrm{M}$.

The measured concentrations of dihydroxyacetone phosphate are in all cases higher than those of glyceraldehyde 3-phosphate, but are still such that any degree of binding [especially as a covalent Schiff base by aldolase (Morse \& Horecker, 1968)] may serve to produce substantial deviation from the keto $\rightleftharpoons$ diol equilibrium as determined in vitro. Similar considerations may also apply in other tissues such as cardiac and skeletal muscle (Table 3). A general scheme of the total number of possible triose phosphate pools is presented in Scheme 4.

Several reports have shown that the dihydroxyacetone phosphate/glyceraldehyde 3-phosphate in many mammalian tissues is markedly displaced from the expected value of 22 (Table 3; Williamson, 1965; Williamson, Kreisberg \& Fetts, 1966; Minakami \& Yoshikawa, 1966). Further, experiments involving gluconeogenesis from deuterated and ${ }^{14} \mathrm{C}$-labelled precursors have demonstrated a lack of isotopic equilibrium at the triose phosphate

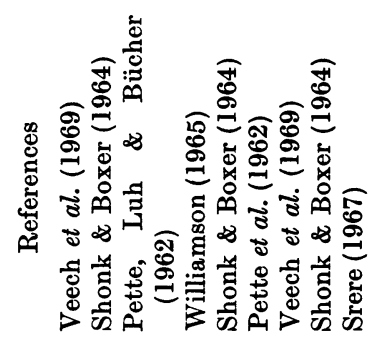



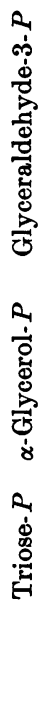

这

융요 낭요 욤

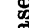

क्ष

입 용

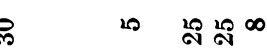

8

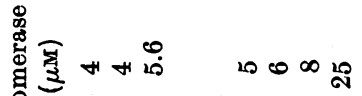

.

总是

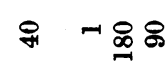

$\overline{1} 0$

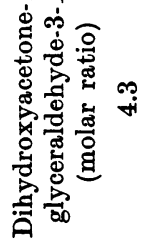

$\dot{s}$

赵要

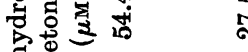

ลิ

คె

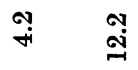

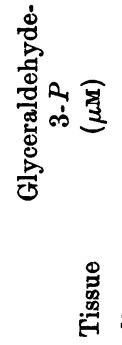

弮

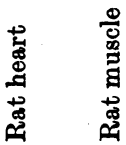




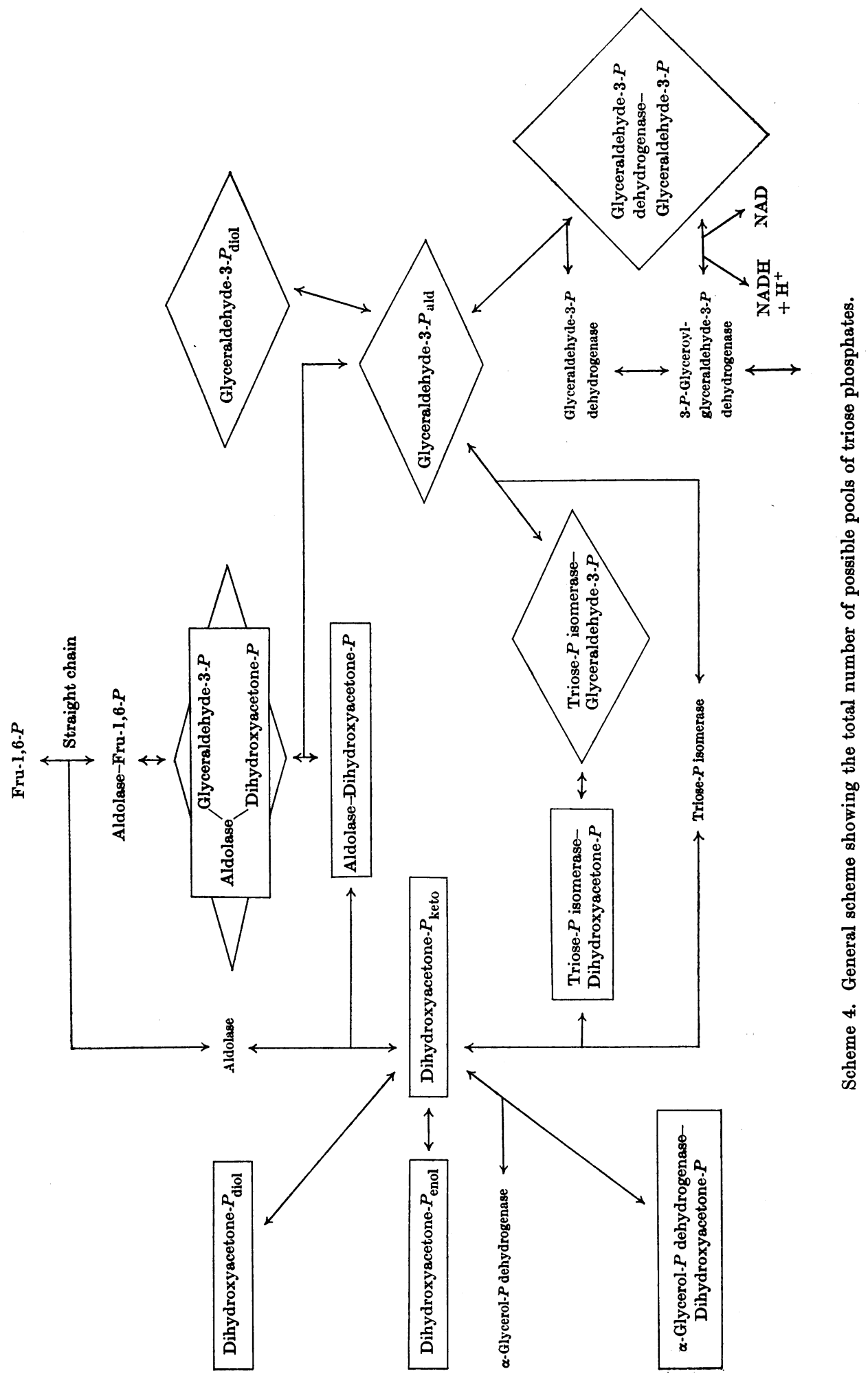




\section{Table 4. Recalculated kinetic parameters for aldolase}

Column A shows values calculated on the assumption that fructose diphosphate is a substrate only when in the straight-chain configuration. Values in column $B$ are based on the assumption that fructose diphosphate may be bound in the furanose form (Gray \& Barker, 1970).

Established value

$K_{\text {eq. }}$.
$K_{m}$
Reference

Rutter (1960)

Morse \& Horecker (1968)

Morse \& Horecker (1968)

Morse \& Horecker (1968)
Recalculated (A) Recalculated (B)

$8.6 \times 10^{-5} \mathrm{M}$

$1.1 \times 10^{-3} \mathrm{M}$

$3.3 \times 10^{-5} \mathrm{M}$

$10^{-6} \mathrm{M}$
$1.4 \times 10^{-6} \mathrm{M}$

$6 \times 10^{-5} \mathrm{M}$ isomerase step in liver (Schambye, Wood \& Popjak, 1954; Landau, Hastings \& Nesbett, 1955; Cahill, Leboeuf \& Renold, 1959; Rose, 1962; Hostetler, Williams, Shreeve \& Landau, 1969), although Katz, Landau \& Bartsch (1966) find that flux rates through triose phosphate isomerase in adipose tissue are sufficient to yield specific activities only 5-20\% from equilibrium. This disequilibrium is further highlighted by the recalculation of the triose phosphate isomerase $K_{\text {eq. }}$ as 420 .

Equilibrium constant of the aldolase reaction. Fructose diphosphate exists in solution largely in the furanose form (Gray \& Barker, 1970). Both direct and indirect evidence suggests, however, that the free keto form of fructose diphosphate is the reactive species in the aldolase reaction (Morse \& Horecker, 1968; Model, Ponticorvo \& Rittenberg, 1968).

Gray \& Barker (1970) have shown that approx. $1.7 \%$ of fructose diphosphate is in the free keto configuration. Bearing this in mind the value for the equilibrium constant of the aldolase reaction becomes $8.6 \times 10^{-5} \mathrm{M}$, compared with the earlier reported value of $8.1 \times 10^{-5} \mathrm{M}$ (Rutter, 1960), an insignificant change. If, however, aldolase binds the cyclic form of fructose diphosphate as suggested by Gray \& Barker (1970) and itself catalyses the necessary ring opening, the equilibrium constant is displaced further from the established value (Table 4). Similar arguments apply to the other kinetic parametres of the reaction.

Although the results in this paper do not in themselves explain the deviation of triose phosphate concentrations from the equilibrium values in vivo, it is thought that they may be used to shed some light on the complex processes that may be involved. In particular, accurate measurements of the binding constants for triose phosphates to the various enzymes together with an understanding of the basic mechanism of action of these enzymes might be employed in the construction of model systems that could aid in distinguishing between the various possibilities available.

We thank Dr K. Kirschner for permission to quote from his manuscript before publication. We thank Dr
D. R. Trentham and Dr H. Gutfreund for discussions and Professor P. J. Randle for his interest and encouragement. This work was supported by a grant from the Agricultural Research Council. C.I.P. is a member of the Medical Research Council Metabolism Control Research Group.

\section{REFERENCES}

Annett, R. G. \& Kosicki, G. W. (1969). J. biol. Chem. 244, 2059.

Ballou, C. E. \& Fisher, H. O. (1956). J. Am. chem. Soc. 78, 1659.

Banks, B. E. C. (1961). J. chem. Soc. p. 5043.

Bell, R. P. (1966). Adv. phys. org. Chem. 4, 1.

Bruice, T. C. \& Benkovic, S. J. (1966). Bio-organic Mechanisms, vol. 1, p. 334. New York: W. A. Benjamin.

Burton, P. M. \& Waley, S. G. (1968). Biochim. biophys. Acta, 151, 714.

Cahill, G. F., jun., Leboeuf, B. \& Renold, A. E. (1959). J. biol. Chem. 234, 2546.

Crutchfield, M. M., Callis, C. F., Irani, R. R. \& Roth, G. C. (1962). Inorg. Chem. 1, 813.

Fleury, P. F. \& Fiévet-Gurnaid, Y. (1947). Annls pharm. fr. 5, 404.

Fleury, P. F. \& Lange, J. (1932). C.r. hebd. Séanc. Acad. Sci., Paris, 195, 1395.

Gardiner, D. (1966). Carbohyd. Res. 2, 234.

Gray, G. R. \& Barker, R. (1970). Biochemistry, Easton, 9, 2454.

Gutfreund, H. (1965). An Introduction to the Study of Enzymes, p. 123. Oxford and Edinburgh: Blackwell Scientific Publications.

Hine, J. (1956). Physical Organic Chemistry, 2nd ed., p. 233. New York: McGraw-Hill.

Hine, J. \& Houston, J. G. (1965). J. org. Chem. 30, 1328. Hooper, D. L. (1967). J. chem. Soc. p. 169.

Hostetler, K. Y., Williams, H. R., Shreeve, W. W. \& Landau, B. R. (1969). J. biol. Chem. 244, 2075.

Katz, J., Landau, B. R. \& Bartsch, G. E. (1966). J. biol. Chem. 241, 7272.

Kiessling, W. (1934). Ber. dt. chem. Ges. 67, 869.

Kirschner, K. (1971). J. molec. Biol. (in the Press).

Kosicki, G. W. (1962). Can. J. Chem. 40, 1280.

Kosicki, G. W. \& Lipovac, S. N. (1964). Can.J. Chem.42, 403.

Krietsch, W. K. G., Pentchev, P. G., Klingenbürg, H., Hofstätter, T. \& Bücher, T. (1970). Eur. J. Biochem. 14, 289. 
Kumler, W. D., Kun, E. \& Shoolery, J. N. (1962). J. org. Chem. 27, 1163.

Landau, B. R., Hastings, A. B. \& Nesbett, F. B. (1955). J. biol. Chem. 214, 525.

Lombardi, E. \& Sogo, P. B. (1960). J. chem. Phys. 23, 635.

Lowry, O. H. \& Passonneau, J. V. (1964). J. biol. Chem. 234, 31.

Malaprade, L. (1928). C.r. hebd. Séanc. Acad. Sci., Paris, 186, 382.

Malaprade, L. (1934) Bull Soc. chim. Fr., Ser. 5, 1, 833.

Meyerhof, O. \& Junowicz-Kocholaty, R. (1943). J. biol. Chem. 149, 71.

Minakami, S. \& Yoshikawa, H. J. (1966). J. Biochem., Tokyo, 59, 139.

Model, P., Ponticorvo, L. \& Rittenberg, D. (1968). Biochemistry, Easton, 7, 1339.

Morse, D. E. \& Horecker, B. L. (1968). Adv. Enzymol. 31, 125.

Pette, D., Luh, W. \& Bücher, T. (1962). Biochem. biophys. Res. Commun. 7, 419.

Racker, E., Klybas, V. \& Schramm, M. (1959). J. biol. Chem. 234, 2510.

Reider, S. V. \& Rose, I. A. (1959). J. biol. Chem. 234, 1007.

Rose, I. A. (1962). J. biol. Chem. 237, 2325.
Rutter, W. J. (1960). In The Enzymes, vol. 5, p. 361. Ed. by Boyer, P. D., Lardy, H. \& Myrbäck, K. New York: Academic Press Inc.

Schambye, P., Wood, H. G. \& Popjak, G. J. (1954). J. biol. Chem. 206, 875.

Schneider, A. S., Valentine, W. N., Hattori, M. \& Heins, H. L. (1965). New Engl. J. Med. 272, 229.

Schwarzenbach, G. \& Wittwer, C. (1947). Helv. chim. Acta, 30, 669.

Sellinger, O. Z. \& Miller, O. N. (1958). Biochim. biophys. Acta, 29, 74.

Shonk, L. E. \& Boxer, G. E. (1964). Cancer Res. 24, 709.

Srere, P. A. (1967). Science, N.Y., $158,936$.

Tate, S. S., Grzybowski, A. K. \& Datta, S. P. (1964). J. chem. Soc. p. 1372.

Telegdi, M. (1964). Acta physiol. hung. 25, 181.

Trentham, D. R., McMurray, C. H. \& Pogson, C. I. (1969). Biochem. J. 114, 19.

Veech, R. L., Raijman, L., Dalziel, K. \& Krebs, H. A. (1969). Biochem. J. 115, 837.

Williamson, J. R. (1965). J. biol. Chem. 240, 2308.

Williamson, J. R., Kreisberg, R. A. \& Fetts, P. W. (1966). Proc. natn. Acad. Sci. U.S.A. 56, 247.

Wolfenden, R. (1969). Nature, Lond., 223, 704.

Wolfenden, R. (1970). Biochemistry, Easton, 9, 3404. 